\title{
EDITORIAL
}

\section{NORTH AMERICA WELCOMES THE WORLD TO THE IAGG WORLD CONGRESS}

\author{
Professor Norah Keating, Chair North American Region of IAGG
}

The World Congress in Gerontology and Geriatrics has been called the 'Olympics of Aging'. Every four years, the world's finest minds in gerontology and geriatrics meet to debate current issues in aging, to discuss groundbreaking research aimed at improving quality of life of older adults and to engage in dialogue about the impact of population aging across regions and cultures. The confluence of disciplines and the diversity of the contexts of aging in which they conduct their research foster an intense and exciting intellectual milieu.

Gerontology is well-established in North America where scholars have been conducting research, developing health and social policy, training new professionals and anticipating the challenges of population aging for many decades. The region is known for its breadth of disciplinary enquiry which encompasses a set of research endeavours from basic biology to macro population trends. In 1960 North America along with Europe became the first official regions of IAGG.

North America's extensive capacity to create knowledge about aging is reflected in the interdisciplinarity of its three member societies. Each is national in scope and multidisciplinary in membership. The Gerontological Society of America is the oldest of our member organizations. Founded in 1945, the GSA was represented in 1949 when the International Association on Gerontology was proposed at the 11th Macy Conference on Aging. It was a founding member of the North American Region in 1960. The GSA mandate is to foster research, education, and practice in the field of aging. GSA members affiliate with one of four sections: Biological Sciences; Health Sciences; Behavioral and Social Sciences; or Social Research, Policy and Practice.

The Canadian Association on Gerontology was founded in the early 1970s by Canadian gerontologists as a vehicle to improve the lives of the older adults through encouraging research in gerontology, disseminating research-based evidence about aging and improving communication and cooperation amongst the many professions and disciplines whose mandate includes older adults. Like the GSA, the Canadian Association on Gerontology is national and multidisciplinary. Members are affiliates of five sections: Health and Biological Sciences, Social Policy \& Practice, Educational Gerontology, Psychology or Social Sciences. Shortly after CAG was founded, it became a member of the North American Region of IAGG.

The Canadian Geriatric Society represents clinicians and researchers in the field of Geriatrics in Canada. Founded in 1981, the Society has the mandate to promote excellence in the medical care of older individuals in Canada, while collaborating with physicians and other health care providers from other specialties/disciplines. The CGS welcomes allied health professionals as associate members. CGS became an organizational member of the North American Region of IAGG in 2004.

The three member societies provide excellent benefits to their members. They publish several peer-reviewed journals:
The Gerontologist, The Journals of Gerontology Series A: Biological and Medical Sciences, The Journals of Gerontology Series B: Psychological and Social Sciences, The Journal of Aging, Humanities, and the Arts, The Canadian Journal on Aging and Canadian Journal of Geriatrics.

Member societies also have special status for student members. Both the GSA and CAG have student sections through which students become engaged in their professional organizations. As well, an important aspect of the work of the Canadian Geriatric Society is to mentor physicians in training who will work with older adults. Because of the strength of its student organizations, the North American Region has been able to share its experiences in fostering strong student involvement in professional societies through promoting the development of strong student organizations in other IAGG regions. There will be a strong presence of students from North America at the Paris World Congress.

North America has been host to a number of IAGG World Congress meetings since the organization's inception in St. Louis (1951), San Francisco (1960), Washington, DC (1969), New York (1985) and Vancouver (2001) all have been World Congress venues. An outcome of the highly successful Vancouver meeting was the establishment of a travel fund to allow students to attend upcoming World Congress events. Twenty students will be supported by the CAG Legacy Fund to attend the Paris World Congress. There are plans to host the 2017 meeting in San Francisco.

We are proud that six eminent North American scholars will give keynote addresses at the Paris World Congress. They represent the diversity and depth of our research culture in aging from medicine to social connections and from macro to micro focus. Two of these plenary speakers will address broad issues of life quality of older adults. Professor Robert Butler will address the conference theme Longevity, health and wealth-pillars of quality of life of older adults and Dr. Réjean Hébert will present evidence of An urgent need to improve life conditions of seniors. Two other presentations will focus on social and clinical issues. Professor Norah Keating will consider the myths and evidence of social connections in Critical reflections on families of older adults and Professor John Morley on Clinical practice in nursing homes as a tool for progress. Two will provide evidence of current breakthroughs in research on frailty: Professor Luigi Ferrucci on the Place of sarcopenia in the frailty syndrome and Professor Michael Weiner on Alzheimer disease new finding from ADNI.

On behalf of all members of the North American Region of IAGG, I would like to welcome you to this $19^{\text {th }}$ World Congress on Gerontology and Geriatrics. May our deliberations be productive and stimulating and provide steps toward improving quality of life for older adults in all regions of the world. 